\title{
Interest rate rules and macroeconomic stabilization
}

\author{
Mark Weder* \\ School of Economics, The University of Adelaide \\ Humboldt-Universität zu Berlin, CDMA and CEPR
}

\section{Introduction}

A well-established fact in monetary theory states that cash-in-advance models tend to display sunspot equilibria for weak degrees of intertemporal substitution (see for example Farmer (1999) in a model with a constant money supply rule). This sort of real indeterminacy gives way for macroeconomic instability to be generated by self-fulfilling beliefs. People's non-fundamental expectations - i.e. beliefs that share no relation to the economy's fundamentals - can affect allocations. The present paper identifies versions of the Taylor interest rate rule that are able to pre-empt these self-fulfilling equilibria. In particular, I show that if the central bank adjusts the short-run nominal interest rate exclusively and passively with respect to future inflation, then sunspots do not matter for any parameter values of relative risk aversion. Phrased alternatively, the enigma of instability caused by certain degrees of risk aversion is completely eliminated by a pure inflation-targeting. However, if output-targeting becomes an issue, then the Taylor rule's timing becomes crucial in deciding how to set the policy parameters. Forward-looking rules generate instability whenever output-targeting is strong. A strong output-targeting is at place when the rule is backward-looking. I also demonstrate that current-looking policies that is rules in which interest rates move with current-period variables always produce indeterminacy. Lastly, I derive observationally equivalent

* This paper was written while I was a DFG Heisenberg Fellow. I would like to thank the Federal Reserve Bank of San Francisco for its hospitality as well as Chuck Carlstrom and one anonymous referee for helpful comments. 
formulations of Taylor interest rules and money growth rules : indeterminacy is not the result of simple nominal money supply rules.

The arguments which are developed in the current paper are framed within a fully specified cash-in-advance environment. It is related to Carlstrom and Fuerst's (2000) analysis of timing-aspects of interest rate rules. My paper differs from theirs in three key aspects, however. First, they limit the analysis to logarithmic utility : preferences alone do not induce multiplicity. Second, in their model the central bank's nominal interest rate targets inflation only. The current paper considers versions of the original Taylor rule in which the interest rate is increased or decreased according to what is happening to both aggregate output and inflation. Furthermore, I present new results on interest smoothing. My work here also shares similarities with Christiano (2000) and Weder (2003) who introduce non-fundamental instability through increasing returns in otherwise standard cash-in-advance economies. They show that certain Taylor rules are able to tax away scale economies and, as a consequence, multiple equilibria disappear.

\section{The artificial economy}

The model is a dynamic general equilibrium economy. It is populated by immortal, atomistic households of measure one. Money is introduced by imposing a cash-in-advance constraint on goods purchases. All markets are perfectly competitive and prices are perfectly flexible. There is no physical capital in the economy - an assumption that is simply made to obtain analytical results. ${ }^{1}$ The baseline specification considers forward-looking Taylor policies : the central bank targets short-run interest rates in response to expected variables. Rules that involve different timings, i.e. current-looking or backward-looking policies, are presented in Section 4. Overall, they tell similar stories.

\subsection{Preferences and technology}

The representative agent's preferences order over an infinite sequence of consumption, $c_{t}$, and labor, $h_{t}$. Lifetime utility is captured by the discounted value of the utility stream:

$$
E_{0} \sum_{t=0}^{\infty} \beta^{t} u\left(c_{t}, h_{t}\right) \quad 0<\beta<1
$$

\footnotetext{
1 The occurence of sunspot equilibria in CIA models does not arise from the absence of capital (see also Carlstrom and Fuerst's (2000) for equivalence results).
} 
where $\beta$ is the discount factor and $E_{0}$ stands for the rational expectations operator. The period-utility is given by

$$
u(., .) \equiv \frac{c_{t}^{1-\sigma}}{1-\sigma}-h_{t} \quad \sigma>0 .
$$

Here, the relative risk-aversion coefficient is denoted by $\sigma$.

Labor is supplied on competitive markets. $W_{t}$ st.ands for the nominal wage. In period $t$ people can invest into a single risk-free asset, $b_{t}$, bearing a gross one-period rate of return $R_{t}$. Alternatively, the agents can set aside cash, $m_{t+1}$. The agent's budget constraint is given by

$$
P_{t} c_{t}+b_{t}+m_{t+1} \leqslant W_{t} h_{t}+R_{t-1} b_{t-1}+m_{t}+N_{t}
$$

where $P_{t}$ denotes the price level and $N_{t}$ is the current period's cash transfer from the central bank.

Money holdings are strictly positive since consumption purchases require cash. The cash-in-advance constraint

$$
P_{t} c_{t} \leqslant m_{t}+N_{t}+R_{t-1} b_{t-1}-b_{t}
$$

states that period $t$ nominal consumption purchases must be covered by the agents' cash holdings. I assume that the asset market opens first : consumption trading is carried out after returning from the financial market and after the current period's cash transfer from the central bank is received.

There is no physical capital in this economy; the production techno$\log y$ is given by

$$
y_{t}=A h_{t} \quad A>0 .
$$

The final good can only be used for consumption purposes.

\subsection{Policy}

The central bank's operating target, $R_{t}$, is set based on the state of macrocconomic variables of the economy. In the baseline specification, I assume that the central bank is forward-looking. The target's movements are synchronized to expected values of inflation and aggregate output :

$$
\hat{R}_{t}=\eta E_{t} \hat{\pi}_{t+1}+\tau E_{t} \hat{y}_{t+1} \quad \eta \geqslant 0, \tau \geqslant 0 .
$$

Carets denote percentage deviations of variables from their stationary state; in a sense, $\hat{y}_{t+1}$ can be interpreted as the output gap. Policies that involve $\eta>1(\eta<1)$ are said to be actively (passively) targeting inflation. Policies that set $\tau>1(\tau<1)$ are active (passive) output-targeting rules. Money supply, $M_{t}^{S}$, adjusts endogenously. The government does not purchase 
goods; any potential seigniorage income is distributed back in lump-sum fashion and does not affect allocations at the margin.

\section{Equilibrium dynamics}

In symmetric equilibrium, $y_{t}=A h_{t}=c_{t}$ and $M_{t}^{S}=m_{t}$ must hold for $\forall t$. The artificial economy boils down to

$$
\beta R_{t} E_{t} c_{t+1}^{-\sigma}=E_{t} \pi_{t+1} c_{t}^{-\sigma}
$$

and

$$
A \beta E_{t} c_{t+1}^{-\sigma}=E_{t} \pi_{t+1}
$$

plus monetary policy (1). Taking a first-order Taylor series approximation around the unique steady state leads to the following linear functional equation

$$
E_{t} \hat{c}_{t+1}=\frac{\sigma}{\eta \sigma-\tau} \hat{c}_{t}
$$

from which the dynamic properties of the economy can be traced. Real determinacy requires that $\left|\frac{\sigma}{\eta \sigma-\tau}\right|>1$. If this condition is fulfilled, the model uniquely pins down the sequence of current and future consumption realizations and non-fundamental noise does not play any role. Otherwise, i.e. if the condition is violated, the rational expectations solution includes

$$
\hat{c}_{t+1}=\frac{\sigma}{\eta \sigma-\tau} \hat{c}_{t}+\left(c_{t+1}-E_{t} \hat{c}_{t+1}\right) \equiv \frac{\sigma}{\eta \sigma-\tau} \hat{c}_{t}+s_{t+1}
$$

in which i.i.d. shocks to expectations, $s_{t+1}$, influence real allocations.

Let us compare the present model to one with an alternative policy: money supply grows at an exogenous rate. Then, the reduced-form dynamics are given by (see Farmer, 1999, or Weder, 2004)

$$
E_{t} \hat{c}_{t+1}=\frac{1}{1-\sigma} \hat{c}_{t}
$$

and sunspot equilibria arise for $\sigma>2$. Consequently, an observational equivalence exists between a constant money growth rule and a forward-looking Taylor policy that sets $\eta^{*}=1-\sigma+\tau / \sigma$ which can easily be seen by comparing (2) and (3).

Next, I will analyze the dynamic implications of Taylor policies other than $\eta^{*}$ - with the goal of identifying parameter constellations in which the indeterminacy disappears. I will begin with the special case of pure inflation-targeting. 


\subsection{Inflation-targeting}

If the central bank targets inflation only, i.e. $\tau=0$, the following result applies: the term that describes relative risk vanishes and, unlike the case of (exogenous) money-growth policies, the degree of relative risk has no effect on the equilibrium dynamics.

However, indeterminacy is still a possibility. A passive (active) inflation-targeting is sufficient for determinacy (indeterminacy). The economics behind the result are easily understood. ${ }^{2}$ If $\eta>1$, the nominal rate and the real interest rate, $r_{t}$, move in the same direction since

$$
\hat{r}_{t}=\frac{\eta-1}{\eta} \hat{R}_{t}
$$

Now, suppose that people increase current consumption - unrelated to any changes in the economy's fundamentals. The consumption surge lowers the real rate as well as the nominal rate. Since the nominal rate is equivalent to a distortion in a cash-in-advance economy, the lower rate is compatible with the initial beliefs. The sunspots cycle is completed. If $\eta<1$, the influence of sunspot expectations remains impossible since deviations from the steady state would violate first-order conditions.

\subsection{Output-targeting}

Let us turn to a pure output-targeting. The dynamics of the economy are given by

$$
E_{t} \hat{c}_{t+1}=-\frac{\sigma}{\tau} \hat{c}_{t}
$$

Unlike the pure inflation-targeting, the elasticity of intertemporal substitution has a first degree influence on the effect of the monetary policy. Indeterminacy arises for $\tau>\sigma$ : a sufficiently weak output-targeting eliminates sunspot equilibria. The following sequence of events depicts the economic reasoning. Assume a belief-driven increase of today's consumption. The expected inflation rate falls. The next period's consumption purchases decline. The new allocation can only be supported as long as today's nominal rate falls. It falls since the drop in future output feeds back into today's nominal rate which will decline. Thus, the initial beliefs are affirmed.

It is noteworthy mentioning that ceteris paribus sunspot equilibria arise for relatively small values of $\sigma$. This circumvents the result obtained in models with a constant money supply rule in which it was low elasticities of intertemporal substitution that lead to multiplicity (see Farmer (1999)). I will show below that this result on macroeconomic stabilization does not

2 Since $\sigma$ drops from (2), the special case of a pure inflation-targeting is, of course, indirectly known from Carlstrom and Fuerst (2000). 
depend on the use of interest rate rules versus money growth rules. The effect is determined by the timing in the policy function under pure outputtargeting. For example, Section 4.2. will demonstrate that when the policy is backward-looking, then large elasticities of intertemporal substitution lead to multiplicity.

\subsection{Output- and inflation-targeting}

Next I will consider the general policy formulation of equation (1). Indeterminacy arises for

$$
\sigma<\tau /(1+\eta) \quad \text { or } \quad \sigma>\tau /(\eta-1) .
$$

The second condition, of course, requires that $\eta>1$. Thus, there is one sunspot zone which can be excluded by passively targeting future-inflation as in Section 3.1. The other zone involves low values of the relative riskaversion parameter. To comprehend my argument's general plausibility, I will turn to a numerical example. Let us assume that the central bank follows the Taylor-principle and, in particular, it sets $\eta=1.53$ and $\tau=0.77$ which are Taylor's (1999) estimates for the Federal Reserve Bank's policy for the 1987-1997 period. ${ }^{3}$ Given Taylor's estimates, determinacy arises for the parametric region $0.31<\sigma<1.45 .{ }^{4}$ Bearing in mind the often used logarithmic period-utility, i.e. $\sigma=1$, one is inclined to conclude that the Taylor-principle is an appropriate policy. However, $\sigma$ may well be located outside the determinacy region. For example, Hansen and Singleton (1983) suggest that the coefficient of relative risk is between zero and two. Thus, information on the true value of $\sigma$ is a pre-requisite for policy advice.

The pre-1980-period is often thought of as having been subject to expectational instability created by the Federal Reserve (see for example Clarida et al. (2000)). Taylor (1999) estimates for the 1960-1979 period are $\eta=0.88$ and $\tau=0.25$. The less than one-for-one weight on inflation is confirmed by other studies (e.g. Clarida et al. (2000)). Now, indeterminacy requires very low and likely unreasonable values of relative risk aversion, i.c. $\sigma<0.13$. In other words, only the first of the above sunspot conditions binds. Given my results, the Federal Reserve's pre-1980 policy may have been a suitable choice in stabilizing expectational fluctuations.

3 Of course, the current economy is likely too simple to take these parameter values at face value. However, the empirical literature has not produced clear point estimations : the estimation uncertainty of the policyestimates is perhaps as large as the variance of $\sigma$-estimates. Thus, my discussion's main intend is to demonstrate that policies that are approximately similar to the observed policies are not able to eliminate sunspots.

4 Note that the results do not depend on the absence of physical capital. For example, in a extension of this model with capital and a Cobb-Douglas technology, the regime shifts at $\sigma=1.45$ as well if the capital share is $0.42, \beta=0.99$, and the capital depreciation rate is 2.5 percent per quarter. Put alternatively, the current paper does not consider physical capital simply to generate analytical results. 


\section{Other versions of the Taylor rule}

This Section presents various extension of the above results. I will begin with the discussion of hybrid rules. This is followed by an analysis of interest smoothing. I will then present results on current-looking and backwardlooking versions of the Taylor rule.

\subsection{Hybrid Taylor rules}

Let us suppose that the central bank's policy is guided by the hybrid rule

$$
\hat{R}_{t}=\eta E_{t} \widehat{\pi}_{t+1}+\tau \hat{Y}_{t} \quad \eta \geqslant 0, \tau \geqslant 0
$$

in which the central bank's operating target is a function of the current output gap. The linear model takes the form

$$
E_{t} \hat{c}_{t+1}=\left(\frac{1}{\eta}+\frac{\tau}{\eta \sigma}\right) \hat{c}_{t}
$$

and determinacy arises if $\tau / \sigma>\eta-1$. This condition implies that the estimated 1987-1997 Taylor parameters $-\eta=1.53$ and $\tau=0.77$ - require that $\sigma>1.45$. The uncertainty about the true value of relative risk aversion implies that the current model cannot answer the question if the Federal Reserve Bank's policy was able to eliminate sunspots. However, if $\eta<1$ (as in line with pre-1980 estimates) then a clear-cut answer is possible. The inequality together with the sign-restrictions on the parameters finds that a hybrid rule that is passive with respect to inflation always produces indeterminacy. In a sense, by reacting to current output - and not to expected output as in Section 3 - the central bank is able to react to both key macroeconomic variables while ruling out indeterminacy at the same time.

\subsection{Interest rate smoothing}

Giannoni and Woodford (2002) have suggested that backward-looking Taylor rules' performances can be improved by adding lagged values of the nominal interest rate. In particular, they consider rules like

$$
\hat{R}_{t}=\rho \hat{R}_{t-1}+\eta E_{t} \widehat{\pi}_{t+1}+\tau \hat{Y}_{t} \quad \rho \geqslant 0, \eta \geqslant 0, \tau \geqslant 0
$$

and find that a smoothing coefficient, $\rho$, greater than one guarantees unique equilibria. The present economy can be approximated by the following equation

$$
E_{l} \hat{c}_{t+1}=\left(\frac{1}{\eta}+\frac{\tau}{\eta \sigma}\right) \hat{c}_{t}-\frac{\rho}{\eta} \hat{c}_{t-1} .
$$


Indeterminacy translates into $1 / \sigma<(\eta+\rho-1) / \tau$. A large smoothing coefficient does not guarantee uniqueness, quite on the contrary, it increases the indeterminacy space. The Clarida et al. (2000) estimates for the pre- and post-Volcker period of the coefficients in equation (4) imply that sunspots arise for $\sigma>0.53$ (and $\sigma>0.47$ ).

\subsection{Current-looking rules}

Let us now formulate the policy

$$
\hat{R}_{t}=\eta \widehat{\pi}_{t}+\tau \hat{Y}_{t} \quad \eta \geqslant 0, \tau \geqslant 0
$$

in which the central bank tunes the short-run rate following movements in the currently observed variables. The dynamics of the economy transform into the scalar equation

$$
(\tau-(1+\eta) \sigma) E_{t} \hat{c}_{t+1}=0 .
$$

This equation pins down $\hat{c}_{t+j} \forall j>0$, however, the initial consumption level is free : real indeterminacy applies for any policy parameter and any degree of relative risk. The finding that current-looking Taylor rules always imply indeterminacy is reminiscent of Carlstrom and Fuerst's (2000) and Weder's (2003) flexible price models which include endogenous investment.

\subsection{Backward-looking rules}

Lastly, I consider a monetary policy that is conducted so as to insure that the nominal rate of interest satisfies

$$
\hat{R}_{t}=\eta \widehat{\pi}_{t-1}+\tau \hat{Y}_{t-1} \quad \eta \geqslant 0, \tau \geqslant 0 .
$$

This rule implies the following dynamics of the economy:

$$
E_{t} \hat{c}_{t+1}=\frac{\sigma \eta-\tau}{\sigma} \hat{c}_{t} .
$$

It is easy to see that there exists an observationally equivalent formulation to an exogenous money growth-policy : the model reduces to (3) if the central bank fixes the Taylor parameters such that $\eta^{*}=1 /(1-\sigma)+\tau / \sigma$.

A unique solution to (6) exists for

$$
\sigma<\frac{\tau}{1+\eta} \quad \text { or } \quad \sigma>\frac{\tau}{\eta-1}
$$

where the second condition only holds for a policy that aggressively works against past inflation. Of course, the conditions in (7) simply reverse the 
ones found for forward-looking rules. This is also reported by Carlstrom and Fuerst (2000) who, however; only consider the special case $\sigma=1$ and $\tau=0$. Given Taylor's post-1979 parameters, i.e. $\eta=1.53$ and $\tau=0.77$, determinacy arises for $\sigma<0.31$ and $\sigma>1.45$. In particular, the economy is indeterminate when period-utility is logarithmic in consumption.

Let us consider two special cases of the backward-looking policy. A purely aggressive inflation-targeting delivers a sunspot-free world and the degree of relative risk does not influence macroeconomic dynamics. On the other hand, strong output-targeting is a strategy that insulates the economy from endogenous cycles. Again, policy implications are flipped on their head when moving from forward-looking to backward-looking rules.

As of late, the Taylor rule debate has advised the monetary authority to assign aggressive configurations of the policy in which interest rates respond to predetermined variables (see for example Carlstrom and Fuerst (1999) and Benhabib et al. (2003)). The current paper challenges that view. Admittedly, the proposal leads to determinacy when the central bank reacts aggressively to past inflation only. Nevertheless, general recommendations for aggressive policies are limited to a certain parametric region. Knowledge of the true value of $\sigma$ is central for submitting concrete policy proposals.

\section{$5 \quad$ Summary}

Recently it has become fashionable to formulate monetary policy in the form of Taylor rules, i.e. it is assumed that the central bank sets the shortrun nominal interest rate in response to macroeconomic variables. The main insight that emerges from the present paper is that Taylor-based monetary policy may be used to eliminate a well-specified source of macroeconomic instability. This is shown within a model in which indeterminacy arises from preferences, i.e. from the intertemporal substitution motive in cash-inadvance economies. However, specific recommendations for monetary policy depend on the fundamentals of the economy. In particular, knowledge of the true value of $\sigma$ remains central before concrete policy proposals can be made. There are only two policies that solve the complete problem : determinacy arises independently of $\sigma$ if the central bank either reacts exclusively to aggressively to past inflation or exclusively passively to expected future inflation. 


\section{References}

Auray, S., F. Collard and P. Feve (2005), "Habit Persistence, Exogenous Money Growth Rule and Real Indeterminacy", Review of Economic Dynamics, 8, pp. 48-67.

Benhabib, J., S. Schmitt-Grohé and M. Uribe (2003), "Backward-Looking Interest-Rate Rules, Interest Rate Smoothing and Macroeconomic Instability", Journal of Money, Credit and Banking, 35, pp. 1379-1412.

Carlstrom, C. and T. Fuerst (2000), "Forward-Looking Versus BackwardLooking Taylor Rules", Federal Reserve Bank of Cleveland Working Paper $n^{\circ} 00-99$, Cleveland.

Carlstrom, C. and T. Fuerst (1999), Forecasts and Sunspots : Looking Back for a Better Future, Federal Reserve Bank of Cleveland Economic Commentary.

Clarida, R., J. Gali and M. Gertler (2000), "Monetary Policy Rules and Macroeconomic Stability : Evidence and Some Theory", Quarterly Journal of Economics, 115, pp. 147-180.

Christiano, L. (2000), "Comment on : Theoretical Analysis Regarding a Zero Lower Bound on Nominal Interest Rates by Bennett T. McCallum", Journal of Money, Credit. and Banking, 32, pp. 870-904.

Farmer, R. (1999), The Macroeconomics of Self-fulfilling Prophecies, 2nd edition, Cambridge, MIT Press.

Giannoni, M. and M. Woodford (2002), "Optimal Interest Rate Rules: II. Applications", Princeton University, mimeographed.

Hansen, L. and K. Singleton (1983): "Stochastic Consumption, Risk Aversion, and the Temporal Behavior of Asset Returns", Journal of Political Economy, 91, pp. 249-265.

Taylor, J. (1999), "A Historical Analysis of Monetary Policy Rules", in John B. Taylor, Monetary Policy Rules, Chicago, Chicago University Press.

Weder, M. (2003), "Taylor Rules and Macroeconomic Instability or How the Central Bank Can Pre-empt Sunspot Expectations", Journal of Money, Credit and Banking (forthcoming).

Weder, M. (2004), "Endogenous Monetary Growth Rules and Determinacy in Cash-in-Advance Models", Economics Bulletin, 5, pp. 1-7. 